\title{
Táticas do cotidiano em Estive em Lisboa e lembrei de você, de Luiz Ruffato
}

\author{
Sara Brandellero*
}

Este artigo analisa a novela Estive em Lisboa e lembrei de você, de autoria de Luiz Ruffato, focando as dinâmicas de poder articuladas na representação do migrante brasileiro e a experiência de deslocamento entendida como política, a partir da figura do protagonista, Sérgio de Souza Sampaio. Mapeando a trajetória deste personagem desde sua cidade natal, Cataguases, até Lisboa, para onde emigra, este estudo dará atenção aos seus trânsitos pelos espaços conhecidos onde nasceu e cresceu e a precariedade de sua experiência como imigrante em Portugal.

As leituras críticas do romance têm se debruçado nas dificuldades associadas à experiência da migração. Rita Godet chama a atenção para o desmonte do "mito do trabalho como elemento de legitimação do fenômeno migratório" (GoDET, 2012, p. 134). Nesta linha, Marco A. Rodrigues discute a representação da "mobilidade precária" dos personagens, que não resulta numa real mobilidade social e sim numa desestabilização de seu senso de identidade (RoDrigues, 2012, p. 181). Cecily Raynor destaca a relação entre o local e o global na narrativa de Ruffato através do conceito de translocalidade que define o posicionamento do protagonista Sérgio num local psicológico entre Brasil e Portugal, num romance definido pela "capacidade de capturar a pluralidade e mesmo a cacofonia de vozes e perspectivas" (RAYNOR, 2015, p. 162). A partir de uma perspectiva afim a estas abordagens críticas centrada na relação entre a figura deslocada e os lugares pelos quais transita, esta leitura da novela de Ruffato se desenvolve a partir das reflexões do sociólogo francês Michel de Certeau, que parecem produtivas tanto para uma leitura temática quanto para a própria construção narrativa do romance.

Em seus reconhecidos escritos sobre as práticas do cotidiano e conceptualizações das deambulações no espaço urbano em seu texto agora referencial $A$ invenção do cotidiano (1998), de Certeau contrasta as estratégias do sistema dominante de controlar os espaços da cidade moderna como as táticas dos usuários comuns do espaço urbano em reescrever as cartografias da cidade segundo as práticas do dia a dia. A figura do pedestre que "reescreve" a geografia da cidade a partir

Doutora em letras e professora de literatura e cultura brasileira da Leiden University, Leiden, Holanda. E-mail: s.l.a.brandellero@hum.leidenuniv.nl 
de sua perspectiva e vivência desde "embaixo", ou seja, as ruas, é, como é sabido, uma peça-chave na elaboração das categorias de de Certeau. Mas de Certeau estabelece também conexões inspiradoras entre as práticas do espaço do sujeito em movimento e, o que interessa particularmente neste ensaio, o próprio ato de enunciação: "O ato de caminhar está para o sistema urbano como a enunciação (o speech act) está para a língua ou para os enunciados proferidos [...] o ato de caminhar parece portanto encontrar uma primeira definição como espaço de enunciação" (Certeau, 1998, p. 177).

Assim, o presente artigo discutirá o imbricamento entre mobilidade e construção da narrativa, mapeando as táticas articuladas pelo personagem em sua negociação de diferentes obstáculos sociais, bem como as próprias táticas narrativas empregadas por Ruffato na viagem intertextual que desfia ao longo da novela, transitando entre vozes canônicas da literatura lusófona e referenciais tirados da cultura popular. Fio temático até agora não devidamente explorado com relação à novela, este ensaio argumentará que o diálogo intertextual elaborado por Ruffato está à base de sua representação da figura do imigrante brasileiro no mundo globalizado da atualidade. Com efeito, esta leitura defende a hipótese de que a representação do imigrante em Ruffato está estritamente ligada ao posicionamento do próprio autor como escritor mineiro deslocado - poderia se dizer que fala das margens - no referencial literário transnacional lusófono. Desta forma, veremos como Ruffato parece desenvolver esta trajetória através do que de Certeau chamaria de caça ilegal, de apropriação subversiva deste mesmo referencial, que se evidencia principalmente em seu diálogo intertextual com o poeta Fernando Pessoa.

\section{O projeto da escrita}

Em 2007, convidados a participar do projeto editorial Amores Expressos, 17 escritores brasileiros foram selecionados para viajar para diferentes cidades do mundo, de Nova York a Shangai, por um período de um mês, com o intuito de, a partir desta experiência, escrever uma narrativa em torno do tema do amor. Organizado pelo produtor Rodrigo Teixeira, o projeto previa a eventual publicação das narrativas pela Companhia das Letras bem como a sua possível adaptação cinematográfica. Entre os participantes convidados, como é sabido, constou Luiz Ruffato, cuja novela resultado da estadia em Portugal intitulada Estive em Lisboa e lembrei de você foi publicada em 2009 e, mais recentemente, adaptada para o cinema pelo diretor José Barahona (2016).

Como o título sugere, a obra tem como fio condutor a experiência da viagem, ou melhor, do deslocamento, neste caso de um homem originário da cidade de Cataguases, em Minas Gerais, que, impulsionado pela falta de oportunidades no interior mineiro, resolve tentar a vida em Portugal. Como lembra Godet, Ruffato 
está especialmente sensível a uma visão de Brasil como país cuja história está intrinsecamente conectada a experiências de deslocamento das pessoas mais pobres - escravos trazidos forçadamente da África, migrantes nordestinos buscando melhores oportunidades de vida no Sul do país; imigrantes portugueses e ondas de imigração da Europa no final do século XIX (2012, p. 132). Em Estive em Lisboa, Ruffato aborda o fenômeno no contexto contemporâneo de uma economia globalizada e de uma substancial emigração brasileira que, desde principalmente os anos 1980 e ainda significativo no início do novo milênio, tem resultado no Brasil como "fornecedor de mão-de-obra barata" oriunda dos grupos marginalizados e periféricos (GODET, 2012, p. 132).

O tema do amor, que orientaria a coleção da Companhia das Letras, não se inscreve de maneira convencional na narrativa, e sim aparece nas ligações afetivas e vários desamores vivenciados pelo protagonista, inclusive no sentimento cada vez mais forte de saudade da terra natal, sofrido em sua vida de imigrante na Europa.

A narrativa se desenrola na voz em primeira pessoa do próprio protagonista, Sérgio de Souza Sampaio, ou Serginho, como logo fica conhecido. Ela se constrói em tom de depoimento, em que Ruffato sustenta uma prosa que parece surgir no próprio ato da fala, numa permeabilidade em que as fronteiras entre a escrita e a voz parecem se esvoar. É através da voz de Serginho que conhecemos seu cotidiano de classe média baixa no Brasil, funcionário da seção de pagadoria da Companhia Industrial de Cataguases, de desempregado, e sua realidade de imigrante ilegal em Portugal. Os títulos das duas partes em que a novela está dividida, "Como parei de fumar" e "Como voltei a fumar", instauram a centralidade da experiência pessoal e do cotidiano na narrativa, através da qual se articula uma reflexão mais ampla sobre o trânsito pelos espaços marginais do mundo contemporâneo.

Nesse sentido, o próprio título da novela aponta para a ironia que estrutura a obra de Ruffato. A referência implícita às frases feitas (anônimas) encontradas nas lembrancinhas e cartões postais turísticos da cidade se justapõe ao tom evidentemente pessoal em que se desenrola a narrativa desde o começo. Com efeito, o título do romance alude ao fenômeno do turismo de massa que Guy Debord, em seu clássico A sociedade do espetáculo (1997), associa à banalização de espaços que acabam perdendo sua autenticidade e a um processo de comodificação que "reduzse, fundamentalmente à distração de ir ver o que se tornou banal" (DEBORD, 1997, p. 168). Se o turismo de massa é frequentemente associado ao que Marc Augé (1995) definiu como "não lugares", espaços esvaziados de especificidades locais significativas contrapostos a lugares antropológicos (Pons; Travlou; CRANG, 2009, p. 9), a voz de Serginho articula a realidade da experiência vivida pelo imigrante brasileiro às margens da legalidade na Europa.

Na primeira parte da novela, conhecemos um Serginho loquaz e irônico, levando uma vida de poucas ambições, namorando "amadoristicamente" (Ruffato, 2009, p. 12), sofrendo a desilusão amorosa pela "certeza de que no 
Brasil vence o mais bem motorizado" (Ruffato, 2009, p. 12). Comentários políticos se misturam com humor e enviesadamente em sua fala, tal quando nos relata suas peladas de fim de semana no time "Primeiro de Abril", sendo o nome uma "dupla homenagem ao Dia da Mentira e à Revolução de 1964, que, na opinião dos colegas mais políticos, dava na mesma" (Ruffato, 2009, p. 16). Homem ingênuo e de poucas ambições, confia na sabedoria do Dr. Fernando "ginecologista e obstetra", que conhece nas peladas dos fins de semana, para tentar se curar do vício do fumo, entregando-se assim a um tratamento que prescreve anticonvulsivante, antidepressivo e uma boa dose de determinação. Ao fim do casamento com Noemi, com quem casa por pressão familiar, segue-se a perda da guarda do filho, Pierre, e, de novo, mais por pressão e expectativas alheias do que uma verdadeira vontade de sair de Cataguases, acaba emigrando. Atualiza-se, assim, a seguir, através da perspectiva de Serginho, uma história de migração brasileira, vista agora sob a perspectiva de quem se vê forçado a sair do país em vez de dos que buscam nele a fortuna. Dessa forma, a mesma minúcia com que mapeia lugares e descreve conhecidos no Brasil, que parece pressupor certa familiaridade por parte do leitor, reaparece no minucioso recorrer dos espaços em que ele tenta se orientar na Europa, onde a sorte do protagonista gradativamente se deteriora, levando-o a voltar a fumar.

Em numerosas entrevistas, Ruffato tem falado do seu desejo de colocar em cena a vida da classe média baixa brasileira, tradicionalmente um ponto cego no panorama literário do país, explorando o que Regina Dalcastagnè definiu como sendo "as potencialidades como discurso desestabilizador e contraditório" da literatura (DALCASTAGNÈ, 2012, p. 17). Em Estive em Lisboa e lembrei de você, o olhar sobre o personagem dessa classe social ganha uma dimensão transnacional, ao dar vulto à figura do migrante, amiúde vista com suspeita e medo, e cada vez mais polarizadora no mundo contemporâneo globalizado e, no entanto, profundamente dividido. Nesse sentido, Ruffato articula o que ele definiu como o "papel transformador da literatura" (RufFATo, 2013), o potencial que oferece de nos familiarizar com o "outro", o que nos é "estranho e que por isso deveria nos despertar o fascínio pelo reconhecimento mútuo, mais que nunca tem sido visto como o que nos ameaça" (Ruffato, 2013). Assim, a partir das formulações de de Certeau sobre a "invenção do cotidiano" e das relações espaciais a partir do sujeito comum em trânsito, pretendo aqui fazer algumas considerações sobre as estratégias narrativas adotadas por Ruffato e da construção das relações espaciais "desde embaixo", como diria de Certeau: "a partir dos limiares onde cessa a visibilidade, [onde] vivem os praticantes ordinários da cidade" (CerTeAU, 1998, p. 171). Estas estratégias parecem se sustentar num diálogo intertextual com o poeta Fernando Pessoa, do qual Ruffato é grande admirador, diálogo esse que, a partir de de Certeau, poderíamos definir de "caça ilegal", como se discutirá a seguir. 


\section{Diálogos pessoanos}

No cerne da narrativa do Ruffato está a experiência do deslocamento, que se traduz tanto no trânsito vivido pelo personagem - sempre em movimento, que parece refletir a precariedade de sua existência à deriva - quanto no destaque conferido à experiência de estranhamento no nível de linguagem. No relato de Serginho, isso se potencializa no uso do itálico para o registro de termos e expressões mineiras ou idiomáticas ou para efeito de ênfase. Na segunda parte da novela, aparece o negrito para destacar expressões do português europeu ou dos imigrantes da África lusófona, com quem Serginho convive nas margens da capital portuguesa.

Gostaria de propor que a busca de Ruffato pela criação de um espaço para esses personagens tradicionalmente esquecidos se dá através de um outro tipo de deslocamento, especificamente através do diálogo proposital com o cânone literário, que se evidencia mais claramente aqui no diálogo intertextual com Fernando Pessoa. Este diálogo parece se inscrever de início sutilmente e de maneira enviesada na nota do autor que aparece nas páginas preliminares da novela de Ruffato:

O que se segue é o depoimento, minimamente editado, de Sérgio de Souza Sampaio, nascido em Cataguases (MG) em 7 de agosto de 1969, gravado em quatro sessões, nas tardes de sábado dos dias 9,16,23,30 de julho de 2005, nas dependências do Solar dos Galegos, localizado no alto das escadinhas da Calçada do Duque, zona histórica de Lisboa. A Paulo Nogueira, que me apresentou a Serginho em Portugal, e a Gilmar Santana, que o conheceu no Brasil, oferto este livro. L.R.

Há no uso das iniciais L.R. desta nota inicial um duplo movimento de inscrição e de ocultamento da figura autoral, em sintonia com a construção do jogo ficcional que aqui se introduz. E parece possível ver na apresentação minuciosa deste personagem-narrador "ficcional" que L.R. articula uma homenagem a Pessoa, um exímio criador de textos como "construtos dramáticos" (CASTRO, 2009, p. 147). ${ }^{1}$ Com efeito, é conhecida a admiração de Ruffato pela obra de Pessoa, e mais pertinente quando lembramos o fato de haver Ruffato organizado uma antologia da obra pessoana um ano antes de participar do projeto Amores Expressos, antologia intitulada Quando fui outro, publicada em 2006 pela Alfaguara, e que na introdução Ruffato mesmo define como um livro "para apaixonados" (Ruffato, 2006, p. 6).

$\mathrm{Na}$ introdução à antologia, sob o título "O homem que tinha urgência de viver", Ruffato comentou sobre sua convivência cada vez mais intensa com a obra de Pes-

\footnotetext{
Parafraseio aqui a definição de Mariana Gray de Castro quando afirma: "Pessoa teria concordado com o fato que o texto é um construto dramático, o qual não pode ser analisado com vistas a identificar nele sinais de vida autoral" (2009, p. 147, tradução nossa).
} 
soa. Os comentários de Ruffato apontam para a sua fascinação com o nível ficcional da obra pessoana: "cresceu em mim a convicção de que, mais que poeta, convivia com um grande ficcionista" (Ruffato, 2006, p. 6). Com efeito, poderíamos argumentar que é possível detectar em Estive em Lisboa e lembrei de você o amor pela obra pessoana como um dos amores em torno dos quais se estrutura a narrativa de um homem lutando contra o hábito de fumar. Esse diálogo é sugerido em sua alusão a uma das composições mais conhecidas de Pessoa. De fato, vale lembrar que o canônico poema "Tabacaria", assinado pelo heterônimo pessoano Álvaro de Campos e com data do ano de 1928, consta como o poema de abertura da coletânea pessoana organizada por Ruffato. Diversas referências à obra pessoana pontuam a narrativa - referências muitas vezes veladas e outras menos e parecem providenciar uma das forças impulsoras dessa viagem narrativa. Assim, poderíamos pensar a novela como surgindo a partir do ato de leitura tal como concebido por de Certeau, como um ato de "caça ilegal" por meio do qual Ruffato assegura sua apropriação do espaço da escrita. A propósito das formulações de de Certeau, cito Anne Marie Chartier e Jean Hébrard: "fazendo da leitura uma arte da caça ilegal, ele (Certeau) a designa como uma ação que quase não deixa traços visíveis [...] ação produtora que [cria] formas singulares de habitar o escrito. A leitura é uma apropriação" (ChARTIER; HÉBrARD, 1998, p. 32).

É a partir de uma "caça ilegal", de uma leitura de Pessoa, poeta canônico, que, pode-se argumentar, Ruffato empreende essa viagem transnacional na conquista de um espaço para a escrita do cotidiano de personagens tradicionalmente excluídos das paisagens literárias brasileiras. Ao mesmo tempo, o diálogo com Pessoa parece definir o posicionamento do próprio Ruffato como escritor que reivindica seu lugar no "território contestado" (DALCASTAGNÈ, 2012, p. 13) da literatura.

Ramos e Cadore apontam para a alusão ao canônico poema "Tabacaria" no desfecho de Estive em Lisboa e lembrei de você. Quando o protagonista Serginho entra numa tabacaria lisboeta e volta a fumar, seu ato parece remeter aos versos pessoanos: "Enquanto o destino me conceder / continuarei fumando" (PessoA, 1987, p. 298). Aprofundando-nos mais no diálogo que Ruffato estabelece com Pessoa, podemos identificar em "Tabacaria" algumas pistas para a origem do personagem de Serginho. Como é sabido, os versos que abrem o poema apontam para o sentimento niilista que parece tomar conta do eu - Álvaro de Campos: "Não sou nada / Nunca serei nada / Não posso querer ser nada” (PessoA, 1987, p. 297). Apesar de Campos achar que a "metafisica é uma consequência de estar mal disposto" (PESSOA, 1987, p. 299), o poema todo é uma tensa, torturada, meditação sobre a morte e sobre o eu, a poesia e imortalidade, o dia a dia, o banal e o além. Olhando as ruas da cidade da janela do seu quarto, Campos visualiza "O Destino a conduzir a carroça de tudo pela estrada de nada", e é no cigarro que ele encontra a "libertação de todas as especulações" (PessoA, 1987, p. 299), a volta ao real. De fato, talvez possamos ver em Serginho um reflexo do "Esteves sem metafísica", que Campos vê saindo da tabacaria em frente de casa e que o traz de volta ao real da materialidade, como lemos no final de "Tabacaria": "Como por um instinto di- 
vino o Esteves voltou-se e viu-me./ Acenou-me adeus, gritei-lhe Adeus ó Esteves! e o universo / Reconstruiu-se-me sem ideal nem esperança e o dono da Tabacaria sorriu" (PESSOA, 1987, p. 300).

É significativo pensar a criação por parte de Ruffato deste personagem mineiro de Serginho a partir da releitura do canônico Esteves pessoano, sobretudo dentro do contexto da inscrição de personagens e lugares tradicionalmente excluídos do mapa literário brasileiro. No relato de Serginho, essa inscrição se sustenta numa tensão narrativa entre o familiar e o estranho, como se evidencia nos trechos finais da primeira parte da novela, em que a irmã Semiramis recomenda Serginho ao motorista de ônibus que o leva ao Rio, ao se despedir do irmão que embarca em Cataguases rumo a Portugal:

"Leva meu irmão direitinho, heim, que ele está indo láááá pra Portugal", e, então, curiosos, os passageiros me cercaram, mesmo os que embarcavam pra outras localidades, Sereno, Santana, Glória, Astolfo Dutra, Ubá, Muriaé, Juiz de Fora, cutucando uns nos outros, "Quem?", "Aquele ali, ó!" [...] cruzamos a ponte nova, flanqueamos a Industrial, atravessamos a Vila Minalda, e, numa curva, depois do Clube Meca, Cataguases desapareceu, e o senhor, sentado ao meu lado, respeitoso, perguntou se viajava a passeio ou a negócio (RufFATO, 2009, p. 36-37).

A condição de deslocado de Serginho é assim enfatizada pelo seu não pertencimento às categorias de turista e homem de negócios, implícitas na pergunta de seu companheiro de viagem. Assim, o cruzar a ponte e o rio Pomba, que atravessa Cataguases, parece consolidar definitivamente a condição de sujeito à deriva de Serginho. Espaço do outro, da exterioridade para de Certeau, o rio é também passagem, e a ponte, para citar de Certeau novamente "ora solda ora contrasta insularidades. Distingue-as e as ameaça. [...] Transgressão do limite, desobediência à lei do lugar, [a ponte] representa a partida, a lesão de um estado, a ambição de um poder conquistador, ou a fuga de um exílio, de qualquer maneira a 'traição' de uma ordem" (CerteaU, 1997, p. 213-214).

A experiência da viagem de avião que se segue a esta "traição" da ordem é emblemática das limitações impostas aos sonhos do personagem de melhorar de vida. O relato do voo transatlântico de Serginho no espaço claustrofóbico do avião, sem ter para onde ir - "perna encolhida, não consegui sossegar sentado" (RUfFATo, 2009, p. 41) - ilustra a real impossibilidade de mobilidade social com que ele se deparará em Portugal, reflexo das barreiras impostas à sua liberdade de transitar na Europa como imigrante ilegal. De fato, a viagem de Serginho confirma o que Doreen Massey definiu como a "geometria de poder" que rege as práticas do espaço no mundo globalizado, em que, se o capital, mercadorias e número cada vez maior de pessoas viaja, é clara a diferenciação de distintos grupos sociais em termos de mobilidade e poder, sendo alguns, tais como os migrantes sem documentos, "efetivamente prisioneiros de sua própria mobilidade" (MASSEY, 1994, p. 3, tradução nossa). 
Já em Lisboa, as andanças de Serginho pela cidade que Ruffato articula oferecem oportunidades para novas incursões na obra de Pessoa. Ao avistar o rio Tejo pela primeira vez, as reflexões de Serginho remetem claramente aos versos do famoso poema do heterônimo e antimetafísico Alberto Caeiro: "O Tejo é mais belo que o rio que corre pela minha aldeia, / Mas o Tejo não é mais belo que o rio que corre pela minha aldeia / Porque o Tejo não é o rio que corre pela minha aldeia" (PessoA, 1986, p. 149). Com efeito, eis o que conta Serginho sobre o episódio, que leva a um dos raros momentos de um pensamento mais reflexivo, aproximandose até do filosófico:

desci a rua, e, especulando, alcancei a beira do Tejo, uma ignorância tanta água, perto dele o infeliz do Pomba parece corguinho, comprei um cartãopostal pra exibir praquele povo incréu de Cataguases, mas às vezes fico pensando, acho que não vou mostrar não, pra que humilhar o pobre do nosso rio?, capaz até adoecer, secar, a gente nunca sabe a reação das pessoas (Ruffato, 2009, p. 43).

As ponderações de Caeiro ficam, assim, antropofagicamente traduzidas para a voz periférica de Serginho, representativa de vozes tradicionalmente excluídas da literatura e que o projeto literário de Ruffato pretende visibilizar através de um diálogo audacioso, uma "caça ilegal" - conforme as formulações de de Certeau com um dos grandes nomes da literatura mundial.

A marginalidade do personagem que Serginho representa dentro da história da literatura brasileira vê-se refletida em sua condição periférica, quando ainda em Minas Gerais, e fica amplificada nos trânsitos pelo espaço urbano lisboeta, para onde emigra. Estes deslocamentos enfatizam a experiência de desorientação e estranhamento perante uma cartografia urbana que lhe é desconhecida: "nisso bati-cabeça o dia inteiro, zanzando de um lado pro outro, avaliando aqueles bitelos de navios ancorados, indagando de uma tal da rua do Vilar, cada hora recebendo uma informação desencontrada" (Ruffato, 2009, p. 43).

Dessa forma, ao descrever os trânsitos lisboetas, e apoiando-se na disjunção linguística entre as variantes portuguesas e brasileiras do português, Ruffato recria em Serginho a figura de um Dante descendo os círculos do inferno (experiência enfatizada pelo uso do negrito na alusão aos "sítios bestiais"), o guia espiritual e intelectual Virgílio aqui aparecendo na figura da Sheila, prostituta brasileira com quem Serginho mantém uma relação amorosa e por quem é eventualmente traído: "Lisboa cheira sardinha no calor e castanha assada no frio, descobri isso revirando a cidade de cabeça-pra-baixo, de metro, de eléctrico, de autocarro, de comboio, de a-pé, sozinho ou ladeado pela Sheila. Com ela como guia visitamos um monte de sítios bestiais" (RufFATO, 2009, p. 67). ${ }^{2}$

\footnotetext{
${ }^{2}$ Ênfase no original
} 
Vemos, na citação acima, a correlação estabelecida entre o ato de caminhar no sistema urbano e o ato de enunciação (o speech act), em que Serginho "descobre" Lisboa desde a perspectiva de "baixo", segundo as formulações de de Certeau, por sua vez articulada numa pluralidade de variantes linguísticas que visibilizam a complexidade do sistema linguístico.

Significativo, nesse sentido, também é o comentário que Ruffato parece fazer sobre a conhecida frase que Pessoa escreveu como Bernardo Soares no Livro do desassossego: "a minha pátria é a língua portuguesa". Esta aparece problematizada no encontro entre Serginho e outro brasileiro, Rodolfo, originário do interior da Paraíba. Apesar de se reconhecerem como brasileiros, o encontro fica logo definido pela dificuldade de comunicação, em que se problematiza não apenas a ideia unificada de nação (brasileira) mas também a de pertencimento dentro do espaço da lusofonia. Ademais, ao avesso do guia turístico, o relato dos passeios com Rodolfo parecem confirmar a impossibilidade real de Serginho de superar o estranhamento do lugar onde reside:

\begin{abstract}
de repente um sujeito me cumprimentou simpático, levantei, "Você é brasileiro?", confirmou, e, satisfeito, eu disse, "Puxa vida, que bom encontrar alguém que fala a mesma língua da gente", apertamos as mãos, "Sérgio de Souza Sampaio, às ordens", apresentei, "Rodolfo...", não entendi o sobrenome, e convidou pra tomar um café [...] e caminhamos, o vento frio na gilete, ele apontava um prédio, uma paisagem, um beco, e explicava, mas eu não entendia quase nada, ele na frente, o rosto embrulhado num cachecol, as palavras saíam abafadas, se perdiam, eu atrás, ouvia apenas "Aqui é o", "Lá embaixo, está vendo?, é a", "O povo daqui é", "Você tem que tomar cuidado com", "Olha o" (Ruffato, 2009, p. 47).
\end{abstract}

Para concluir, é oportuno refletir sobre o alcance e as implicações das incursões de Ruffato na obra de Pessoa para a sua criação dos espaços literários no contexto migratório em Estive em Lisboa e lembrei de você, sobretudo levando em consideração a preocupação do autor mineiro em fazer da literatura um espaço de inclusão. De fato, os trânsitos intertextuais por que Ruffato orienta sua narrativa de viagem transnacional sustentam seu projeto literário de conceder maior visibilidade a vidas e vozes brasileiras negligenciadas ao longo da história da literatura brasileira. O processo de criação parece desvendar um duplo transpor de fronteiras. Se, para o personagem de classe média baixa que Ruffato põe em cena na figura do Serginho, as fronteiras legais continuam intransponíveis e sua "traição à ordem" é reduzida apesar da mobilidade física, Ruffato opera uma audaciosa "caça ilegal" como leitor de Pessoa, transitando por diferentes textos pessoanos e diversos heterônimos para construir e ocupar o seu espaço, e assegurar o de seus personagens, na literatura.

Sendo o próprio Ruffato autor de origem de classe média baixa cuja vida foi transformada pelo contato com a literatura (RuffATo, 2013), o diálogo com Pessoa 
revela ao mesmo tempo o respeito ao mestre canônico e a irreverência do escritor que pretende desestabilizar as relações tradicionais entre literatura e poder. Para citar de Certeau, podemos ver na página em branco, o da literatura, um espaço onde se possibilita a afirmação de um sujeito autoral: "Diante de sua página em branco cada criança já se acha posta na posição do industrial ou do urbanista, ou do filósofo cartesiano - aquela de ter que gerir o espaço, próprio e distinto, onde executar um querer próprio" (CERTEAU, 1997, p. 225).

\section{Referências}

AugÉ, Marc. Non-places: introduction to an anthropology of supermodernity. Tradução de John Howe. London; New York: Verso, 1995.

Castro, Mariana Gray de. Pessoa and the modernist tradition. In: Parkinson, Stephen; Earle, Thomas; Pazos-Alonso, Cláudia (Ed.). Companion to Portuguese literature. Oxford: Legenda, 2009.

Certeau, Michel de. A invenção do cotidiano. Tradução de Ephraim Ferreira Alves. Petrópolis: Vozes, [1980] 1998.

Chartier, Anne-Marie; Hébrard, Jean. A invenção do cotidiano: uma leitura, usos. Tradução de Mariza Romero. Revisão técnica de Yara Aun Khoury. Projeto História, São Paulo, v. 17, p. 29-44, 1998. Disponível em: <https://revistas.pucsp.br/index. php/revph/article/view/11107/8151>. Acesso em: 16 jun. 2017.

Dalcastagné, Regina. Um território contestado: literatura brasileira contemporânea e as novas vozes sociais. Iberic@l, Paris, n. 2, p. 13-18, 2012. Disponível em: <http://iberical.paris-sorbonne.fr/wp-content/uploads/2012/o3/oo2-02.pdf>. Acesso em: 25 maio 2017.

Debord, Guy. A sociedade do espetáculo. Rio de Janeiro: Contraponto, [1967] 1997.

Godet, Rita O. Entre o chão encontrado e o chão perdido: Estive em Lisboa e lembrei de você, de Luiz Ruffato. Aletria, Belo Horizonte, v. 22, n. 3, p. 131-138, 2012. Disponível em: <http://www.periodicos.letras.ufmg.br/index.php/aletria/article/ view/3854 $>$. Acesso em: 25 maio 2017.

Massey, Doreen. A global sense of place. In: Massey, Doreen. Space, place and gender. Minneapolis: University of Minnesota Press, 1994. Disponível em: $<$ https://www.unc.edu/courses/20o6spring/geog/o21/oo1/massey.pdf >. Acesso em: 25 maio 2017.

PessoA, Fernando. Obra poética. Rio de Janeiro: Nova Aguilar, 1986.

Pons, Pau O.; Travlou, Penny; Crang, Mike. Cultures of mass tourism: doing the Mediterranean in the age of banal mobilities. Farnham; Burlington: Ashgate, 2009. 
Ramos, Tânia Regina Oliveira; CAdore, Amanda. Desamores expressos - Estive em Lisboa e lembrei de você. Navegações, Porto Alegre, v. 3, n. 2, p. 148-153, jul./dez. 2010. Disponível em: <http://revistaseletronicas.pucrs.br/ojs/index.php/ navegacoes/article/view/8434>. Acesso em: 15 maio 2017.

RAYNor, Cecily. Linguagem, espaço e nação: um mapeamento das identidades multigeográficas do protagonista imigrante. Estudos de Literatura Brasileira Contemporânea, Brasília, n. 45, p. 159-182, jan./jun. 2015.

Rodrigues, Marco Antonio. Mobilidade precária em Terra estrangeira e em Estive em Lisboa e lembrei de você. Estudos de Literatura Brasileira Contemporânea, Brasília, n. 39, p. 181-192, jan./jun. 2012.

Ruffato, Luiz. O homem que tinha urgência de viver. In: PessoA, Fernando. Quando fui outro. Antologia. Organização de Luiz Ruffato. Rio de Janeiro: Alfaguara, 2006.

Ruffato, Luiz. Estive em Lisboa e lembrei de você. São Paulo: Companhia das Letras, 2009 .

Ruffato, Luiz. Discurso para a abertura da Feira de Frankfurt, em 8 de outubro de 2013. Disponível em: <https://goo.gl/DN891d>. Acesso em: 16 jun. 2017.

Recebido em 30 de outubro de 2017.

Aprovado em 24 de março de 2018.

\section{Resumo/Abstract/Resumen}

Táticas do cotidiano em Estive em Lisboa e lembrei de você, de Luiz Ruffato

\section{Sara Brandellero}

Este artigo analisa a novela Estive em Lisboa e lembrei de você, de autoria de Luiz Ruffato, focando as dinâmicas de poder articuladas na representação do migrante brasileiro e a experiência de deslocamento entendida como política, centrada na figura do protagonista, Sérgio de Souza Sampaio. A partir das formulações sobre as práticas do espaço urbano e da leitura de Michel de Certeau, o artigo defende a hipótese de que a representação do migrante em Ruffato está estritamente ligada ao posicionamento do próprio autor como escritor mineiro deslocado, que fala das margens, no referencial literário lusófono. Assim, o artigo discute como, através do que de Certeau chamaria de "caça ilegal", de apropriação subversiva deste mesmo referencial, evidencia-se principalmente o diálogo intertextual com o poeta português Fernando Pessoa.

Palavras-chave: Luiz Ruffato, migração, prática do espaço, intertextualidade. 
Tactics of daily life in Estive em Lisboa e lembrei de você, by Luiz Ruffato

\section{Sara Brandellero}

This article analyzes the novella Estive em Lisboa e lembrei de você, by Luiz Ruffato, focusing on the power dynamics articulated in the representation of the figure of the Brazilian migrant and the experience of displacement understood as political, centred on the figure of the protagonist, Sérgio de Souza Sampaio. Taking our cue from the formulations by Michel de Certeau on urban spatial practices and the act of reading, the article argues that the representation of the migrant by Ruffato is closely connected with the author's own positioning as a displaced author from Minas Gerais, who speaks from the margins of the Lusophone literary landscape. Thus, the article will argue that through what de Certeau would term the 'illegal hunt', in the case of Ruffato the subversive appropriation of Lusophone literary references, an intertextual dialogue with the Portuguese poet Fernando Pessoa becomes apparent.

Keywords: Luiz Ruffato, migration, spatial practices, intertextuality.

Tácticas de la vida cotidiana en Estive em Lisboa e lembrei de você, de Luiz Ruffato

\section{Sara Brandellero}

Este artículo analiza la novela Estive em Lisboa e lembrei de você, de la autoría de Luiz Ruffato, enfocando las dinámicas de poder que se articulan a través de la representación del migrante brasileño y de la experiencia del desplazamiento entendida como política, centrada en la figura del protagonista, Sérgio de Souza Sampaio. A partir de las formulaciones sobre las prácticas en el espacio urbano y sobre la lectura propuestas por Michel de Certeau, este trabajo postula que la representación del migrante en Ruffato está estrechamente vinculada al posicionamiento del autor como escritor minero (de Minas Gerais) desplazado que habla desde el margen, en el contexto literario de lengua portuguesa. De este modo, el artículo defiende que mediante lo que de Certeau definiría como "caza ilegal”, una apropriación subversiva de ese mismo referencial literario, se evidencia especialmente el diálogo intertextual con el poeta portugués Fernando Pessoa.

Palabras clave: Luiz Ruffato, migración, prácticas del espacio, intertextualidad. 